\title{
A MATEMÁTICA NOS CURSOS DE CIÊNCIAS NO SUL DO MATO GROSSO UNO
}

\author{
Kátia Guerchi Gonzales? \\ Carla Regina Mariano da Silva ${ }^{2}$ \\ Antonio Vicente Marafioti Garnica ${ }^{3}$
}

\section{RESUMO}

Neste artigo, nosso propósito é analisar aspectos de como a Matemática se configurava nos cursos de Ciências que, no sul do Mato Grosso Uno, tinham por finalidade formar professores. Para a discussão, recorremos às compreensões resultantes de duas teses de Doutorado, uma das quais, tematiza as Licenciaturas em Ciências e em Matemática, no estado de Mato Grosso do Sul, nos campus da UEMT - Universidade Estadual de Mato Grosso e da FADAFI - Faculdade de Filosofia Dom Aquino, em torno da década de 1970; enquanto a outra estuda as Licenciaturas Parceladas de Ciências e as Licenciaturas em Regime Parcelado de Ciências - Habilitação em Matemática, implantadas, respectivamente, nas décadas de 1970 pela UEMT, e em 1990 pela UFMS - Universidade Federal de Mato Grosso do Sul. O estudo dessas produções considera o sul do Mato Grosso Uno e sua realidade sociocultural e política, permitindo observar, dentre uma pluralidade de subtemas de discussões, a Matemática presente nessas modalidades de formação de professores. Ressaltamos, assim, que as disciplinas relativas à Matemática, nessas distintas modalidades de ensino, seguiam praticamente as mesmas disposições e pressupostos e, com uma mesma nomenclatura e carga horária, eram efetivadas de modos muito distintos nos processos de formação.

Palavras-chave: Formação de professores de Matemática. Mato Grosso Uno. Professores Leigos.

\footnotetext{
'Doutora em Educação Matemática pela UNESP de Bauru, docente da Uniderp Anhanguera. Orcid iD: https://orcid.org/0000-0003-2827-2545. E-mail: profkatiaguerchi@gmail.com

2Doutora em Educação Matemática pela UNESP de Rio Claro, docente da Universidade Federal de Mato Grosso do Sul (UFMS). Orcid iD: https://orcid.org/0000-0003-3591-0242. Email: carla.silva@ufms.br

32Doutor em Educação Matemática pela UNESP de Rio Claro, Livre-docente pelo Departamento de Matemática da UNESP de Bauru, docente dos Programas de Pósgraduação em Educação Matemática (UNESP-Rio Claro) e Educação para a Ciência (UNESP-Bauru). Orcid iD: https://orcid.org/0000-0003-0750-8483. E-mail:
} vicente.garnica@unesp.br 


\title{
MATHEMATICS IN SCIENCE COURSES IN THE SOUTH OF MATO GROSSO UNO
}

\begin{abstract}
The purpose of this article is to perform an analysis of how Mathematics was configured in the science courses which the main purpose was teachers education. Such courses under consideration here were developed in the south of Mato Grosso Uno. For this discussion, we took as source the results obtained in two doctoral theses: one of them studying undergraduate courses in science and mathematics developed in the state of Mato Grosso do Sul, at the UEMT - Mato Grosso State University - and FADAFI - Faculty of Philosophy Dom Aquino, around the 1970s; the other one focuses on Parceled Courses in Sciences and the Parceled Regime of Formation for Sciences - qualification in Mathematics developed respectively in the 1970s by UEMT and in 1990 by UFMS - Federal University of Mato Grosso do SUl. These two productions consider the South of Mato Grosso Uno in its socio-cultural and political reality allowed us to observe the mathematics present in such modes of teacher education, bringing light to a plurality of sub-themes. The disciplines related to Mathematics offered in those two distinct modalities of teaching education courses, were practically the same, with the same titles and workload, yet they were carried out in very different ways.
\end{abstract}

Keywords: Teacher training in Mathematics. Mato Grosso Uno. Teachers with no undergraduate and specific formation.

\section{LA MATEMÁtICA EN LOS CURSOS DE CIENCIAS EN EL SUR DEL MATO GROSSO UNO}

\section{RESUMEN}

En este artículo, es nuestro propósito realizar un análisis de como la Matemática se configuraba en los cursos de Ciencias que, en el sur del Mato Grosso Uno, tenían por finalidad formar profesores que enseñaban Matemáticas. Para la discusión, recurrimos a los resultados obtenidos en dos tesis de Doctorado: una de ellas es un estudio de las de Licenciaturas en Ciencias y en Matemáticas en el estado de Mato Grosso do Sul, ocurrida en los campus de la UEMT - Universidad Estadual de Mato Grosso y de FADAFI - Facultad de Filosofía Don Aquino, en torno a la década de 1970; la otra, objetiva estudiar las Licenciatrías Parceladas de Ciencias y las Licenciaturas en Régimen Parcelado de Ciencias - habilitación en Matemáticas, ocurridas respectivamente en las décadas de 1970, por la UEMT, y en 1990 por la UFMS - Universidad Federal de Mato Grosso do Sul. El estudio de esas producciones considera el sur de Mato Grosso Uno y su realidad sociocultural y política, y permite observar, entre una pluralidad de subtemas de discusiones, la Matemática presente en tales modos de formación de profesores. Las disciplinas matemáticas ofrecidas en las dos modalidades de enseñanza eran prácticamente las mismas, con los mismos nombres y con la misma carga horaria, pero, sin embargo, se realizaban de maneras muy diferentes.

Palabras clave: Formación de profesores de Matemáticas. Mato Grosso Uno. Profesores Laicos. 


\section{INTRODUÇÃO}

Os estudos sobre formação de professores de Matemática no Brasil, como salienta Martins-Salandim, Fernandes e Garnica (2011), têm nos mostrado que o complexo e amplo sistema educacional brasileiro, organizado segundo diversas reformas ocorridas no decorrer do tempo, constitui-se, a partir da divisão por níveis de ensino, comportando diferentes modalidades específicas de formação, tipos de instituições, legislações, etc., que se propõem, até os dias atuais, a facultar uma formação que vai além dos conhecimentos a serem mobilizados no ofício do magistério. Esse cenário, não poucas vezes intrincado e caótico, devido às variações geográficas e culturais de um país de proporções continentais, fomentou o surgimento de diversos modelos de formação de professores para atender as demandas específicas de cada contexto.

Nosso olhar, neste texto, foca um desses cenários, qual seja, a formação de professores que ensinam/ensinavam Matemática no Sul do Mato Grosso Uno. Para isso, nos debruçamos em duas pesquisas que focam os primeiros cursos, nesta região, voltados à formação docente. Uma dessas pesquisas, intitulada Uma, Nove ou Dez Narrativas sobre as Licenciaturas em Ciências e Matemática em Mato Grosso do Sul, buscou investigar os movimentos de criação e funcionamento de Licenciaturas em Matemática e Ciências no Mato Grosso do Sul. A outra, sob o título Formar professores que ensinam Matemática: uma história do movimento das Licenciaturas Parceladas no Mato Grosso do Sul, tratou de compreender aspectos das chamadas Licenciaturas Parceladas que habilitavam professores para ensinar Matemática e foram oferecidas pela Universidade Estadual do Mato Grosso - UEMT - e pela Universidade Federal de Mato Grosso do Sul, respectivamente, nas décadas de 1970 e 1990. As duas pesquisas trabalharam segundo os pressupostos da História Oral, tendo sido entrevistados, para a primeira pesquisa, nove ${ }^{4}$ colaboradores, e treze 5 para a segunda.

4 Foram entrevistados por Silva (2015): Conceição Aparecida Galves Butera, Edson Norberto Cáceres, Gilberto Antônio Telarolli, Maria Helena Junqueira Caldeira, Edson Rodrigues De

Revista Exitus, Santarém/PA, Vol. 9, № 4, p. 665 - 694, Out/Dez 2019. 
Como os cursos de formação de professores tomados como foco nessas pesquisas foram desenvolvidos em meados da década de 1960 e na década de 1970, concomitante à divisão do estado do Mato Grosso Uno, pensamos ser importante entender não só aspectos dessas décadas, mas também suas cercanias, para o que incluímos aqui recortes de uma narrativa histórica acerca do movimento divisionista e das ações políticas que se efetivaram para que a divisão fosse pensada, proposta e, efetivamente, ocorresse. Assim, inicialmente procuramos situar o contexto sóciohistórico e político do sul do Mato Grosso Uno, aludindo a algumas de suas características e peculiaridades posto ter sido esse o contexto que permitiu a criação das licenciaturas aqui estudadas.

Num segundo momento, discutimos aspectos da estrutura interna das Licenciaturas de Ciências, tanto as "regulares" quanto as "parceladas", da década de 1970; e, por fim, tecemos considerações acerca das questões que permeavam as licenciaturas e o modo como a Matemática foi nelas implementada visando a atender determinado público alvo, ressaltando as intenções e as estruturas institucionais que deram suporte à criação, à implementação e ao desenvolvimento desses cursos.

\section{O CONTEXTO SUL MATO-GROSSENSE: UM ESTADO CRIANDO FORMA E UNIVERSIDADES}

Abordar temas de estudo que envolvam a história de Mato Grosso do Sul implica, de pronto, um olhar de abrangência mais amplo, que deve ir até ao Mato Grosso Uno, que acolheu os habitantes e as terras hoje divididas em dois estados: o Mato Grosso e o Mato Grosso do Sul. As regiões norte e sul do antigo Mato Grosso, entretanto, nunca foram, uma única e mesma coisa, com uma história comum, uma vez que sua formação geográfica,

Carvalho, Eronides de Jesus Biscola e Jair Biscola, Celso Correia De Souza, José Luiz Magalhães De Freitas e Carlos Henrique Patusco.

$5 \mathrm{Na}$ pesquisa desenvolvida por Gonzales (2017) foram entrevistados: Carlos Henrique Patusco, Masao Uetanabaro, Sérgio Delvízio Freire, Luiz Carlos Pais, José Luiz Magalhães de Freitas, Sidnei Azevedo de Souza, Edmir Ribeiro Terra e Celso Correia de Souza, Antônio Lino Rodrigues de Sá, Maria Luiza da Silva Correa, Antônio Enes Nonato, Gilberto Luiz Alves e Antônio Carlos do Nascimento Osório. 
"acentuadamente alongada no sentido longitudinal gerou, ao longo do tempo, duas formações históricas distintas de modo a justificar o uso dos termos norte e sul, mais salientes do que em qualquer outra unidade federativa brasileira" (BITTAR, 2009, p. 36). O contexto que antecede a divisão do estado nos permite compreender as ações políticas e a articulação de um regionalismo que resultou nesse desmembramento.

Nos anos de 1960 havia uma grande disputa pela hegemonia do poder político e econômico entre Campo Grande (sul) e Cuiabá (norte). As mídias em Campo Grande apresentavam a cidade como soberana no que diz respeito ao desenvolvimento, parecendo não haver, no estado, outra cidade capaz de superá-la, sequer alcançá-la. As arrecadações municipais eram sempre destacadas nas constantes publicações sobre o assunto, mostrando que, em 1963, Campo Grande arrecadava quase que o dobro da capital, Cuiabá (BITTAR; SILVA; VELOSO, 2003).

Apesar de Campo Grande aparentemente ser mais desenvolvida que a própria capital, até o ano de 1962 havia instituições de ensino superior apenas em Cuiabá. De acordo com Both (2014), o conflito que existia entre Cuiabá e Campo Grande, na luta pela capital, intensificou-se ainda mais quando estas duas cidades começaram a lutar também pela implantação de uma Universidade Federal. Tal fato, nas palavras de Bittar, Silva e Veloso (2003, p.149), foi o "que incentivou as lutas pró-divisão". Esse movimento de divisão que acompanhou o Mato Grosso Uno por diversas décadas refletiu também na criação dos cursos superiores no sul do estado que, desde meados de 1950, tentava instituir o ensino superior e só instalou sua primeira instituição dessa natureza em 1961.

Esse espaço geográfico e político que hoje conhecemos como o estado de Mato Grosso do Sul - na época, Sul de Mato Grosso - foi o cenário para o desenvolvimento da educação no centro-oeste do país. Especificamente, a formação "regular" de professores de Matemática começa a ocorrer no final da década de 1960, com a criação do curso de Ciências, Licenciatura Curta, em Institutos de Educação Superior distribuídos pelo interior da região sul, posteriormente reunidos, em 1970, com a criação 
da Universidade Estadual de Mato Grosso - UEMT. Esses cursos de Ciências habilitavam profissionais para atuarem nas disciplinas de Ciências e Matemática no chamado, a partir da LDB de 1971, Ensino de $1^{\circ}$ grau.

Antes mesmo da criação desses cursos que ofereciam uma formação institucionalizada, há indícios, na região, da atuação de professores leigos e de professores formados em cursos feitos pela CADES 6 nas cidades de Campo Grande e Corumbá durante a década de 1960. Além disso, o intenso processo migratório nas décadas de 1960 e 1970 cuidou de prover ao sistema profissionais formados nas mais diversas áreas para atuar como professores no que chamamos, hoje, de Educação Básica.

Ainda que a formação em Matemática em cursos regulares tenha se iniciado apenas ao final da década de 1970, os cursos de Pedagogia e Letras foram criados em 1961, no Centro de Educação Superior da Faculdade Dom Aquino de Filosofia Ciências e Letras (Fadafi), hoje Universidade Católica Dom Bosco. O curso de Ciências só foi criado em 1970, e as habilitações em Matemática e Biologia dez anos mais tarde, na mesma instituição, então denominada Faculdades Unidas Católicas de Mato Grosso (FUCMT).

A Universidade Estadual de Mato Grosso, instituição que daria origem à atual Universidade Federal de Mato Grosso do Sul (UFMS), foi criada em 1970, agregando o Instituto de Ensino Superior de Corumbá e criando os Centros Pedagógicos de Aquidauana, Três Lagoas e Dourados. Essa criação foi precedida pela Faculdade de Farmácia e Odontologia de Mato Grosso que, para abrigar o curso de Medicina, tornou-se, em 1966, Instituto de Ciências Biológicas de Campo Grande.

O atual campus da Universidade Federal de Mato Grosso do Sul em Aquidauana - à época Centro Pedagógico de Aquidauana - foi criado em agosto de 1970 e deu início às suas atividades em 1971, passando a integrar a Universidade Estadual de Mato Grosso com os cursos de Letras em duas

\footnotetext{
${ }^{6}$ Campanha de Aperfeiçoamento e Difusão do Ensino Secundário.

${ }^{7}$ A portaria n 736 , de 30 de Dezembro de 1981, do Ministério da Educação e Cultura, reconhece o curso de Ciências, Licenciatura Plena, com as habilitações em Matemática e Biologia que já funcionavam desde 23 de Julho de 1979.
} 
opções, Português e Português/Inglês, e Estudos sociais. Em 1973 foi criado o curso de Ciências, Licenciatura para o $1^{\circ}$ grau, as habilitações de Português (25 vagas) e Português/Inglês (15 vagas) e as habilitações de História (20 vagas) e Geografia (20 vagas), como habilitações dos cursos de Letras e Estudos Sociais, respectivamente. O curso de Ciências, segundo o Parecer $n^{\circ}$ 051/1973 do Conselho Estadual de Educação do Estado do Mato Grosso, foi criado de acordo com as normas que regiam, à época, a Reforma Universitária, e justificado, segundo esse parecer, devido às necessidades do magistério e da Lei 5692/1971. A criação do curso se seguiu a reformulações na Estrutura Curricular que parecem terem sido feitas de modo a adequar-se à Resolução 30/1974, do Conselho Federal de Educação, que estabelecia o currículo do curso de Ciências, Licenciatura em $1^{\circ}$ grau. O curso de Licenciatura em Matemática foi criado apenas em 1996, tendo sido suas atividades iniciadas no ano letivo de 1997.

Já o Centro Pedagógico de Dourados, segundo Faoro (2014), foi criado pela lei 2.972, de 02 de Janeiro de 1970, e a escolha dos cursos que seriam ali oferecidos foi feita, a partir de uma pesquisa realizada a fim de buscar quantos e quais eram os profissionais de que a cidade necessitava, à época. Assim, o Centro Pedagógico de Dourados deu início às suas atividades com os cursos de Letras e Estudos Sociais. Posteriormente, em 1975, foi criado o curso de Ciências, Licenciatura em $1^{\circ}$ grau. Em 1978 criouse o curso de Agronomia e em 1979 o de Pedagogia. Ainda que o curso de Ciências tenha sido criado em 1975, somente em 1984 foram criadas suas habilitações em Biologia e Matemática e, pouco tempo depois, em 1987, os cursos de Licenciatura em Matemática e em Biologia. Em Corumbá, a formação de professores teve seu início com a criação do Instituto Superior de Pedagogia de Corumbá, criado em meados de 1968, com forte apoio de Salomão Baruki, que convenceu alguns profissionais de outras áreas que ali trabalhavam a lecionar nos cursos de Ciências, Letras, História e Pedagogia.

Em atas do Conselho Universitário - COUN - do ano de 1974, Ramez Tebet, à época, professor em Três Lagoas e posteriormente, prefeito de Três Lagoas e senador do Estado, propôs a criação, nos moldes do que era 
oferecido em Aquidauana, de um curso de Ciências para a formação de professores de Matemática, Biologia, Química e Física nos campus da UEMT. No entanto, a UEMT em Campo Grande, devido a seu recém-criado curso de Engenharia, havia contratado alguns professores de Matemática que lutavam pela criação de um curso de Matemática. Devido a esse interesse, os professores do Departamento de Matemática de Campo Grande recusaram-se a criar um curso de Ciências para formar professores na UEMTCampo Grande, e somente em 1981 o curso de Licenciatura em Matemática foi criado.

O Centro Pedagógico de Rondonópolis foi criado em 1976, e atualmente ele pertence à UFMT. Rosa (1993) menciona que os centros Pedagógicos foram implantados em regiões estratégicas, o que se pode notar no mapa a seguir, visando ao desenvolvimento do estado, com a finalidade de preparar recursos humanos.

Figura 2: Mapa da localização dos Centros Pedagógicos no sul do Mato Grosso Uno

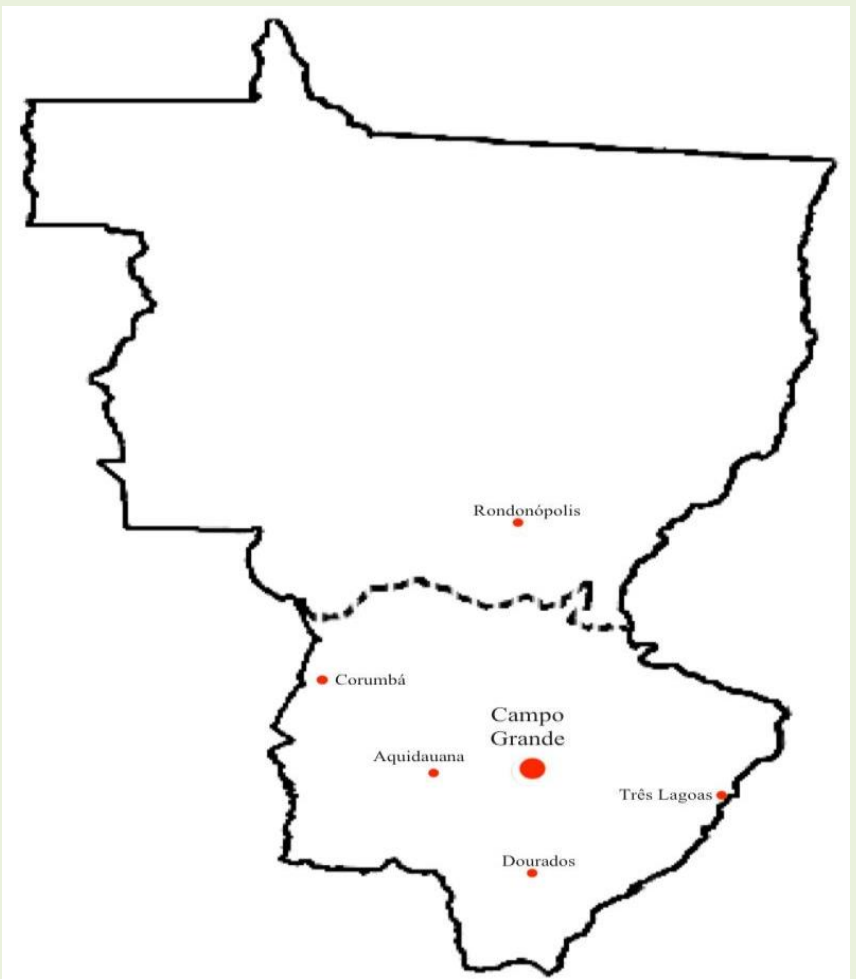

Fonte: Figura elaborada pelos autores. 
A distribuição dos Centros criados no final da década de 1960, início da década de 1970, mostra que, havia nesse período, cursos para formar professores de matemática em quase todas as regiões do estado, estando de fora apenas a região nordeste. Nesta região, foram criados no final da década de 1990, cursos de Ciências em Cassilândia e, na década de 2000, em Paranaíba.

O predomínio de cursos de Ciências, ao invés de cursos de Matemática, foi um aspecto destacado na pesquisa de Silva (2015). Os cursos de ciências foram, ainda, a única formação oferecida na modalidade parcelada, como se pode conferir em Gonzales (2017). Assim, trazemos à discussão, agora, o que previa a legislação educacional dessa época, que parece ter determinado a abertura desses cursos nesse espaço do território brasileiro.

\section{OS CURSOS DE CIÊNCIAS NO CENTRO-OESTE BRASILEIRO}

A LDB n. ${ }^{\circ} 4024,20 / 12 / 1961$ exerceu um papel importante na expansão do ensino superior no país com a criação do Conselho Federal de Educação (CFE) e do Conselho Nacional de Educação, composto pela Câmara de Educação Básica e pela Câmara de Educação Superior. O CFE deveria deliberar sobre assuntos pertinentes ao ensino primário, médio e superior e o Conselho Nacional de Educação, de maneira geral, deveria prestar assessoria ao Ministério da Educação sobre assuntos pertinentes a quaisquer níveis de ensino.

Assim, a partir de 1961, o CFE passou a deliberar sobre o ensino superior e a formação de professores, estabelecendo um currículo mínimo para as licenciaturas, ao qual foram vinculadas as disciplinas pedagógicas deveriam ser oferecidas, pelo menos, uma em cada semestre. Essa medida, ao menos do ponto de vista formal, marcou o fim do sistema conhecido como $3+1$ instituído pela reforma Francisco Campos.

Durante os anos que se seguiram, pareceres e resoluções modificaram as estruturas propostas pela lei 4024/1961, e é nesse período que surgem os cursos de curta duração como uma alternativa direcionada à formação de 
professores. A duração de um curso de graduação era indicada em anos, sem menção alguma à carga horária anual mínima necessária, o que é confirmado no parecer de Newton Sucupira, disponível na Revista Documenta, $n^{\circ} 31$, de 1964, no qual fica estabelecido que cursos de curta duração eram aqueles realizados em três anos, assim como os bacharelados. Segundo Castro (1974), em 1965 uma portaria ministerial ( $n^{\circ}$ 159 de 14/06/1965) determinava que a carga horária dos cursos superiores fosse contada em horas-aulas, ao invés de ser computada pelo número de anos de estudos. Essa mesma portaria fixou os tempos mínimo e máximo para a integralização dos cursos:

As licenciaturas variam. Entre as destinadas ao exercício docente
no primeiro ciclo, a carga horária oscila entre 2.025 hs e 2.430 hs. As
mais longas são as de História Natural e Pedagogia com 3.240
horas, e as demais ficam entre 2.880 hs e 2.700 hs. A Integralização
média é de 3 ou de 4 anos, respectivamente para as mais curtas e
mais longas (CASTRO, 1974, p.640).

Essa divisão por carga horária é a que utilizamos até hoje, ainda que os mínimos e os máximos tenham sido modificados no decorrer dos anos. Apesar da possibilidade de se oferecer cursos de curta duração já ter sido anunciada em 1964 pelo, à época, Conselho Federal de Educação, é apenas na década de 1970 que eles passam a ser discutidos e implementados com maior intensidade. A lei 5692/1971, em seu artigo 30, permite que o professor com licenciatura curta ministre aulas até a $8^{a}$ série do ensino do $1^{\circ}$ grau, correspondente, até aquele momento, ao antigo primeiro ciclo do ensino médio, o ginasial. Essa mesma lei cria os núcleos comuns: Curso de Ciências para as licenciaturas em Matemática, Física, Química e Biologia, com o intuito de possibilitar a instituição de uma Ciência Integrada. Quando os cursos de curta duração foram citados, em 1964, como disposto no parecer de Newton Sucupira, eles surgiam como mais uma medida emergencial para a formação de professores. Em 1971, o que era até então medida emergencial foi tornada oficial e seria, alguns anos depois, tornada obrigatória. 
Valnir Chagas, membro do Conselho Federal de Educação à época da publicação da Lei 5692/1971, com o intuito de motivar a execução dessa Lei, discute a formação do magistério nesse novo sistema. Para Chagas (1976), os cursos de curta duração se justificam devido às diferenças culturais de cada região do País. Estabelecido um currículo mínimo, em locais "onde ocorra maior oferta de meios, aos sistemas será lícito condicionar o exercício profissional dos licenciados a um preparo superior aos mínimos estabelecidos..." (CHAGAS, p. 16, 1976). A Formação de professores seria feita de forma progressiva: em um primeiro momento se obtinha uma habilitação geral, com a Licenciatura em Ciências, e depois uma habilitação específica. Seguindo a LDB, três pareces dispunham sobre como dar-se-ia a criação e a implementação de cursos de curta duração para formar professores. O parecer CFE 22/1973 ditava as normas a serem seguidas por todas as licenciaturas, e previa três núcleos de conhecimentos. Para áreas de Educação Geral, os campos que compreendiam a formação de professores para atuarem no ensino de $1^{\circ}$ e $2^{\circ}$ grau eram três: Ciências, Estudos Sociais e Comunicação e Expressão. Para a área/curso de Ciências, as habilitações eram aquelas a que já nos referimos anteriormente: Matemática, Física, Química e Biologia. Para a área/curso de Estudos Sociais, as habilitações eram Geografia, História, Organização Social e Política Brasileira (OSPB) e Educação Moral e Cívica. A área de Comunicação e Expressão era mais ampla, contemplando três cursos: Letras, Educação Artística e Educação Física. Para a área de Letras, as habilitações eram Língua Portuguesa, Língua Estrangeira Moderna e Língua Clássica. Para o curso de Educação Artística, as habilitações eram Música, Artes Plásticas, Desenho e Artes Cênicas, e para o curso de Educação Física, as habilitações eram Ginástica e Atletismo, Técnica Desportiva e Recreação.

Com essa concentração, havia apenas cinco cursos voltados à formação docente, o que ampliaria, segundo Chagas (1976), o campo de atuação do professor e tornaria o mercado de trabalho mais flexível, além de haver um melhor aproveitamento dos recursos humanos. Chagas argumenta ainda que a formação de professores, segundo essa disposição 
progressiva, era mais adequada para o sistema de ensino de $1^{\circ}$ e $2^{\circ}$ grau que então havia sido implementado, e que era necessário haver professores polivalentes para a integração dos estudos, uma vez que sem docentes devidamente preparados, pouco se conseguiria para atingir esse objetivo.

A resolução 30, como é conhecida a Resolução do CFE nº 30 de 11 de Julho de 1974, tornou obrigatória, a partir de 1978, a condensação das licenciaturas, de maneira que a formação de professores passou a ser feita a partir das áreas que o CFE 22/1973 previa, além de ter estabelecido um currículo mínimo para os cursos, haveria uma parte comum a todas as áreas, uma parte diversificada e momentos voltados à instrumentalização para o Ensino. A parte comum deveria abranger as matérias/atividades de Matemática, Física, Química, Elementos de Geologia e Biologia. Já na parte diversificada, haveria uma seleção de matérias/atividades para cada habilitação. A habilitação em Matemática deveria conter Cálculo Diferencial e Integral, Álgebra, Análise Matemática, Geometria, e Matemática Aplicada; a habilitação em Física deveria conter as matérias de Matemática, Química, Física e Física Aplicada; enquanto a habilitação em Química conteria Matemática, Física, Química Geral, Química Inorgânica e Química Orgânica e Biológica; e, por fim, a habilitação em Biologia compreenderia as disciplinas de Biologia Geral, Botânica, Zoologia, Ecologia, Bioquímica e Biofísica. A Instrumentação para o Ensino seria o espaço reservado nos cursos, à formação pedagógica.

O último parecer que entendemos ter sido de suma importância para a criação de cursos que formavam professores no país, é a Resolução CFE 37/1975 que dispunha, no parágrafo único de seu artigo 1, sobre a obrigatoriedade de converter todas as licenciaturas em Matemática, Física, Química e Biologia, em Licenciaturas Ciências (polivalente) até o ano de 1978. Ainda que tendo sido revogada pela Resolução CFE 05/1978, nos importa essa discussão visto que nossa análise será efetivada considerando duas estruturas curriculares: aquela proposta para o ano de 1976 para um Curso regular de Ciências, licenciatura curta, e aquela proposta para um 
Curso parcelado de Ciências, licenciatura curta, ambos oferecidos na Universidade Estadual de Mato Grosso(atual UFMS).

Em um primeiro momento, tendo sido criados como medida emergencial, os cursos de curta duração foram responsáveis pela formação da maioria dos professores que atuaram na educação básica brasileira durante certo período.

Em Mato Grosso do Sul, na década de 1970 todos os cursos que formavam professores de Matemática eram de curta duração, posteriormente transformados em cursos de Licenciatura em Matemática, em meados de 1987. Silva (2015) estudou três desses cursos criados nas cidades de Corumbá (UFMS), Três Lagoas (UFMS) e Campo Grande (UCDB). O curso de Ciências criado em Dourados (UFMS) foi tema de estudo de Faoro (2014) e o curso de Ciências de Aquidauana (UFMS) completa 0 quadro dos cursos a serem, aqui, considerados.

À época, também surgiram programas, como o Programa de Expansão do Ensino Médio - Premem -, com o propósito de implantar Escolas Polivalentes 8 e, consequentemente, formar professores em cursos de curta duração. Em conformidade com a legislação de então, segundo Both (2014), foram criadas Escolas Polivalentes em todo o país, uma vez que a reforma educacional prevista pela Lei 5.692/1971 pretendia preparar os alunos para $o$ mercado de trabalho tornando o ensino de Primeiro e Segundo Graus (atualmente, Ensino Fundamental e Médio) não somente obrigatório, mas também profissionalizante, visando a atender a sociedade com mão-de-obra qualificada. Formavam-se, assim, por esses Programas, professores que, estando ou não vinculados à rede de ensino, deveriam

\footnotetext{
${ }^{8}$ As primeiras Escolas Polivalentes, no Brasil, foram implantadas em 1971, entrando assim, em funcionamento, durante o Regime Militar, "no contexto político internacional da Guerra Fria agindo na América Latina" (ARAÚJO, 2011, p. 51). Assim, estas escolas foram criadas a partir do programa da Aliança para o Progresso, por meio de acordos entre a USAID (Agência Norte-Americana para o Desenvolvimento Internacional e o MEC (Ministério da Educação e Cultura). Este modelo de escola, de acordo com os estudos de Araújo (2011), foi cópia das escolas públicas para excluídos sociais existentes, à época, nos EUA. No Brasil, tinham como papel a formação em massa de trabalhadores para a nova realidade de produção do país. Contudo, segundo Both (2014), devido os vultuosos montantes necessários à sua manutenção, seja em relação aos recursos humanos, físicos e financeiros, essas Escolas Polivalentes foram extintas.
} 
atuar nas Escolas Polivalentes depois de terem concluído o curso intensivo, desenvolvido em 42 semanas consecutivas.

Em Cuiabá, foi criada com tal finalidade a Escola Polivalente Santos Dumont que, anteriormente, chamou-se de Escola Polivalente de Cuiabá. Para atender essa escola, a Secretaria de Educação do Estado, por meio de um processo seletivo, enviou 10 profissionais - cinco para o curso de Matemática e cinco para o curso de Ciências - para, de Setembro de 1971 a junho de 1972, cursar a Licenciatura de Curta Duração ofertada pelo Premem e desenvolvida pelo Centro de Ensino de Ciências do Nordeste Cecine, em parceria com a Universidade Federal de Pernambuco - UFPE. Ressalvamos, porém, que esse era um curso específico para atender a uma demanda também específica da então capital mato-grossense, Cuiabá (BOTH, 2014).

Para atender os leigos em atuação, que também necessitavam de formação específica, surgiram, no interior do estado, mais especificamente, no sul do Mato Grosso Uno, as Licenciaturas Parceladas de Curta Duração. Visando à formação de professores para atuar no ensino de $1^{\circ} \mathrm{grau}, \mathrm{a}$ diferenciação entre essa modalidade de cursos e os demais se anunciava já na própria nomenclatura: essas licenciaturas ocorriam parceladamente, nos períodos de férias escolares e feriados.

O idealizador do projeto das Parceladas, o professor Gilberto Luiz Alves, percebia que um dos problemas do ensino público, naquele período, era a falta de formação específica dos professores:

Pesquisas têm demonstrado que deficiências constatadas na produtividade do ensino são, em grande parte, consequências devidas às próprias limitações do professorado. Em Mato Grosso temos tido oportunidade de, constantemente, assinalar o despreparo técnico-pedagógico de nossos leigos e normalistas do Ensino Primário, e também de nossos professores do Ensino Médio (ALVES, 1973, p.17).

Neste mesmo texto, o professor Gilberto Luiz Alves expressa a necessidade de interferir mais incisivamente na preparação de professores, administradores e supervisores para o Ensino Primário, dar ênfase a este nível 
de ensino, ressaltando que outras modalidades de cursos de treinamento para os professores leigos, que antecederam o projeto das Parceladas, não foram eficientes para manter os professores na profissão. Destaca, ainda, o processo de evasão em massa do magistério por parte de cursistas e professores treinados que, nas palavras dele, devia-se a dois principais motivos: a inexistência de um suporte legal que forçasse o reconhecimento e a institucionalização de novos padrões de formação de professores leigos, e a falta de equiparação, em termos salariais, do professor leigo treinado ou em processo de treinamento. A evasão implicava a necessidade de absorção de novos leigos, totalmente despreparados. Contudo, o texto salienta que a situação das redes escolares das Prefeituras Municipais tinha um problema ainda maior, já que a cada mudança de administração os leigos treinados eram preteridos por pessoas menos qualificadas?. Pelos motivos destacados, Alves (1975) argumenta que, como consequência, os professores treinados continuavam na condição de leigos, mesmo tendo um melhor nível de instrução, já que o treinamento puro e simples, sem a contrapartida do reconhecimento e de equiparação salarial, não é um mecanismo eficiente para manter os professores na rede.

Os Centros Pedagógicos também desempenharam esse papel de oferecer cursos de ensino superior para os jovens das regiões distantes da capital ou dos grandes centros, mais especificamente voltados à formação de professores. Contudo, mesmo para acessar os Centros Pedagógicos, localizados no interior, com cursos noturnos para a formação de professores, como era o caso de Corumbá, os professores leigos não conseguiam deslocar-se diariamente devido ao trabalho e às estradas precárias. O intuito dos Centros era atender a demanda de ensino de $1^{\circ} \mathrm{e} 2^{\circ}$ graus, já que houve um aumento significativo da população do estado nas décadas de 1960 e

\footnotetext{
${ }^{9}$ Bonilla (1962) assinala que, já na década de 1960, havia esse problema, e menciona que alguns municípios e escolas rurais permaneciam como feudos políticos no que diz respeito à educação: a nomeação do professor dependia especificamente da lealdade política ao candidato e à sua família, e a maior parte dos professores designados para a função não possuía nenhum preparo.
} 
1970. Todavia, Silva (2015) destaca a marginalização dos Centros Pedagógicos:

[...] gera-se e alimenta-se um movimento de criação, nas cidades, digamos, centrais, como Campo Grande e Dourados, de cursos de Engenharia, Agronomia e Medicina, enquanto nas cidades periféricas (Corumbá, Três Lagoas e Aquidauana) são criados cursos que formam professores, estruturalmente mais "singelos" por não exigirem gastos com laboratórios e instalações muito sofisticadas além das já usualmente existentes (SILVA, 2015, p.185).

A estrutura das Licenciaturas oferecidas nos Centros Pedagógicos, como menciona Silva (2015), era bastante singela, até mesmo insignificante, como salienta o professor Carlos Henrique Patusco ao mencionar que, neles, inicialmente, as aulas eram ministradas em prédios emprestados. Depois, mesmo com prédios próprios para as Licenciaturas Parceladas, a Universidade não tinha estrutura alguma nos polos "para abrigar os alunos e nem para os professores lecionarem", lembra o professor Masao Uetanabaro. Por esse motivo, sendo as aulas ministradas nos períodos de férias, aproveitavam-se os colégios nas cidades para que os cursos ocorressem.

As Licenciaturas Parceladas foram pensadas originalmente de modo que os professores atuantes na rede pública tivessem acesso a processos de qualificação profissional sem que a comunidade por eles atendida fosse prejudicada com suas ausências no cotidiano escolar. O público das Parceladas - ao contrário do que ocorria com a Licenciatura de Curta Duração "regular" - era composto por leigos, muitos apenas com formação de $2^{\circ}$ grau ${ }^{10}$, que já lecionavam nas redes públicas devido à carência de docentes habilitados em suas respectivas regiões. Ainda que o público fosse outro, o objetivo dos cursos de Ciências - tanto os que ocorriam na forma que aqui chamamos "regular", quanto os parcelados - era formar professores de matemática para atuar no Ensino de $1^{\circ}$ grau. A lei 5691/1971

\footnotetext{
10 De acordo com os artigos 22 e 23 da lei $n^{\circ} 5692$ de 11 de Agosto de 1971, o Ensino de $2^{\circ}$ grau era composto por três ou quatro séries. A conclusão da $3^{a}$ série habilitava o aluno a prosseguir os estudos no ensino superior, e a $4^{a}$ série, quando equivalente, poderia ser aproveitada no curso superior de mesma área ou áreas afins. Em 1996, a lei n 9.394, em seu art. 35, modificou a nomenclatura dessa etapa final da Educação Básica para Ensino Médio, mantendo três anos como a duração mínima.
} 
previa que, em lugares nos quais não houvesse professores formados, poderiam atuar aqueles que tivessem a mesma escolaridade para a qual o curso visava formar docentes, o que possibilitava, portanto, que aqueles formados em Ciências atuassem no Ensino de $2^{\circ} \mathrm{grau}$, e que aqueles com formação no $2^{\circ}$ grau também pudessem lecionar nesse nível de ensino.

As dificuldades - mencionadas pelos professores colaboradores - dos alunos que faziam o curso, eram visíveis: alguns deles não tinham formação alguma e, mesmo assim, lecionavam no ensino básico por falta de professores. Como tratava-se de um curso de Ciências que envolvia Matemática, Física, Química e Biologia, o diploma dava direito, segundo os nossos colaboradores, a lecionar em qualquer uma dessas áreas, o que era bom para o estado já que se formava um único professor para atuar em diversas frentes. O aluno Antônio Enes Nonato, por exemplo, assinala: "Esse curso era justamente para suprir as vagas em Matemática, Biologia, Química e Física. Depois de concluí-lo, lecionei Física, Química e Estatística no segundo grau, contudo, me formei em Matemática para o primeiro grau" (Entrevista do aluno Antônio Enes Nonato).

Em contrapartida, os alunos que atuavam em qualquer uma dessas áreas podiam fazer o curso para lecionar no Ensino Fundamental. Por esse motivo, apesar dos nossos colaboradores afirmarem que muitos tinham facilidade com os conteúdos da área de Exatas, nem sempre gostavam ou tinham afinidade com a Matemática, o que também é destacado pelo aluno Antônio Enes Nonato: "Matemática mesmo não foi bem por opção, eu fui ser professor para suprir as vagas". Sendo assim, na visão do professor Sérgio Delvizio Freire, o professor de Matemática que lecionava nas Parceladas "tinha um trabalho a mais para fazer a pessoa gostar. Tinha que conquistar o aluno, fazer com que ele gostasse, passe a gostar de Matemática. Mostrar que a Matemática não é um bicho de sete cabeças", já que o curso era polivalente.

Focando mais especificamente dois cursos de Ciências oferecidos no estado - aquele da cidade de Aquidauana na, à época, UEMT e o oferecido por essa mesma instituição de modo parcelado - tecemos, no que 
segue, algumas comparações que objetivam apontar diferenças e semelhanças desses dois modos de formação de professores de Matemática que operaram na década de 1970 no Sul do estado de Mato Grosso.

Essas comparações foram feitas tendo como fontes os documentos oficiais dos cursos em foco e as entrevistas disponíveis nos textos que aqui nos servem de apoio. Esses materiais nos permitem entender as estruturas curriculares dos cursos regulares e parcelados de Ciências, dos quais os dois acima citados são tidos como exemplos, sem haver prejuízo na análise, posto que os demais cursos funcionavam, cada qual em sua modalidade e natureza, seguindo as mesmas diretrizes. Em um primeiro momento, nosso olhar volta-se à legislação que possibilitou a criação e a manutenção dos cursos de curta duração de Ciências. A partir das estruturas, observaremos a nomenclatura e a carga horária das disciplinas ofertadas nas duas modalidades de ensino. Focaremos, por fim, os modos e tempos de execução, além de discutir as disciplinas matemáticas que compunham um curso que, segundo as disposições mais gerais, tinha como objetivo considerar uma ciência integrada, visando a uma formação mais adequada ao ensino de $1^{\circ}$ e $2^{\circ}$ grau.

\section{ESTRUTURA DO CURSO DE CIÊNCIAS REGULAR}

Ainda que houvesse certas recomendações para pensar a estrutura curricular de um curso de licenciatura curta, foi somente após a publicação da Resolução CFE 30/1974 que orientações mais objetivas sobre o Curso de Ciências foram disponibilizadas. Dos cinco cursos "regulares" de Ciências que havia no estado, na década de 1970 - Aquidauana (UEMT/UFMS), Corumbá (UEMT/UFMS), Dourados (UEMT/UFMS), Três Lagoas (UEMT/UFMS) e Campo Grande (FUCMT/UCDB) -, discutiremos aqui o primeiro deles por haver indícios bastante claros, nas fontes consultadas, de que a estrutura curricular elaborada para o ano de 1976 visava a atender o que dispunha a já referida Resolução.

Com uma proposta na qual a ideia de ciência integrada era central, a Resolução 30 previa a obrigatoriedade do oferecimento de disciplinas na 
parte comum de Matemática, Física, Química, Elementos de Geologia e Biologia. Vemos, no entanto, que além dessas, na estrutura curricular do curso de Ciências regular, havia a disciplina de Prática Desportiva em todos os semestres do curso, além das disciplinas Estudo de Problemas Brasileiros I e II, Introdução ao Estudo de Língua Portuguesa, Psicologia Educacional, Didática, e Métodos e Técnicas de Pesquisa I e II. As disciplinas Prática de Ensino de Ciências e Estágio Supervisionado, e Estrutura e Funcionamento de Ensino de $1^{\circ}$ e $2^{\circ}$ graus eram mencionados na Resolução e estavam presentes na estrutura estudada.

Quadro 1: Estrutura Curricular do Curso de Licenciatura em Ciências, Campus de Aquidauana para o ano de 1976 (conforme a resolução 30/74 do CFE).

\begin{tabular}{|c|c|}
\hline \multicolumn{2}{|c|}{$1^{\circ}$ semestre } \\
\hline Disciplina & Carga horária \\
\hline Fundamentos de Matemática I & 90 \\
\hline Biologia Geral I & 60 \\
\hline Desenho Geométrico e Geometria Descritiva I & 60 \\
\hline Psicologia Educacional I & 60 \\
\hline Estudo de Problemas Brasileiros I & 30 \\
\hline Prática Desportiva I & 30 \\
\hline Métodos e Técnicas de Pesquisa I & 60 \\
\hline Introdução ao Estudo da Língua Portuguesa & 45 \\
\hline \multicolumn{2}{|c|}{$2^{\circ}$ semestre } \\
\hline Disciplina & Carga horária \\
\hline Fundamentos de Matemática II & 90 \\
\hline Química Geral & 60 \\
\hline Biologia Geral II & 60 \\
\hline Desenho Geométrico e Geometria Descritiva II & 60 \\
\hline Didática I & 60 \\
\hline Estudo de Problemas Brasileiros II & 30 \\
\hline Prática Desportiva II & 30 \\
\hline \multicolumn{2}{|c|}{$3^{\circ}$ semestre } \\
\hline Disciplina & Carga horária \\
\hline Álgebra I & 60 \\
\hline Trigonometria & 60 \\
\hline
\end{tabular}




\begin{tabular}{|c|c|}
\hline Física Geral e Experimental I & 60 \\
\hline Química Inorgânica I & 60 \\
\hline Botânica Geral I & 60 \\
\hline Biologia Geral III & 60 \\
\hline Prática Desportiva III & 30 \\
\hline Métodos e Técnicas de Pesquisa II & 45 \\
\hline \multicolumn{2}{|l|}{$4^{\circ}$ semestre } \\
\hline Disciplina & Carga horária \\
\hline Álgebra II & 60 \\
\hline Física Geral e Experimental II & 60 \\
\hline Química Inorgânica II & 60 \\
\hline Química orgânica I & 60 \\
\hline Zoologia Geral I & 60 \\
\hline Botânica Geral II & 60 \\
\hline Prática de Ensino de Ciências Estágio Supervisionado I & 60 \\
\hline Prática Desportiva IV & 30 \\
\hline \multicolumn{2}{|l|}{$5^{\circ}$ semestre } \\
\hline Disciplina & Carga horária \\
\hline Física Geral e Experimental III & 60 \\
\hline Química orgânica II & 60 \\
\hline Zoologia Geral II & 60 \\
\hline Elementos de Geologia & 60 \\
\hline Elementos de Estatística & 60 \\
\hline Estrutura e Funcionamento de Ensino de $1^{\circ}$ e $2^{\circ}$ graus I & 60 \\
\hline Prática de Ensino de Ciências Estágio Supervisionado II & 60 \\
\hline Prática Desportiva $\vee$ & 30 \\
\hline ELETIVA & 45 \\
\hline Total Geral de Carga Horária: & 2205 \\
\hline Total Geral de Créditos & 147 \\
\hline
\end{tabular}

Fonte: Acervo da UFMS - Universidade Federal de Mato Grosso do Sul

$\mathrm{Na}$ estrutura curricular do curso regular de Ciências, acima apresentada, a carga horária de disciplinas que identificamos como "disciplinas matemáticas" somavam 150h no primeiro semestre, 150h no segundo, 120h no terceiro, $60 \mathrm{~h}$ no quarto e, por fim, 60h no quinto (tomando 
Elementos de Estatística como disciplina relacionada à Matemática). No total, havia 540h de disciplinas diretamente ligadas à Matemática, sendo que a divisão entre as demais disciplinas era a que segue: $420 \mathrm{~h}$ para as disciplinas de Biologia, 300h para as disciplinas de Química, 180h para a disciplina de Física e 60h para as disciplinas relacionadas à Geologia. Desse modo, é visível a desproporção da quantidade de carga horário dedicada a cada uma das disciplinas que compunham a parte comum do curso de Ciências: à Matemática cabia uma maior parte do bolo.

\section{ESTRUTURA DO CURSO DE CIÊNCIAS PARCELADO}

Buscamos compreender a estrutura interna das Licenciaturas Parceladas em Ciências no interior de Mato Grosso. Tais cursos eram oferecidos em fases, sendo que em Ponta Porã e Rondonópolis houve quatro fases, divididas da seguinte forma: em Ponta Porã, a primeira fase aconteceu em julho de 1973, a segunda em janeiro de 1974, a terceira em julho de 1974 e a quarta e última deu-se em janeiro e fevereiro de 1975; em Rondonópolis, a primeira fase realizou-se em julho de 1973, a segunda em janeiro de 1974 e as terceira e quarta fases em janeiro e fevereiro de 1975. No total, um ano e meio de curso.

Concluída a primeira experiência, tendo sido formada apenas uma turma em cada polo, em 1975, discutiu-se não somente a continuidade dos cursos das Licenciaturas Parceladas de Curta Duração, mas também a criação de outros cursos em outras sedes. A partir dessas discussões do Conselho de Ensino e Pesquisa da UEMT surgiu a proposta de realizar cursos nessa modalidade em Glória de Dourados ${ }^{11}, C_{\text {Cáceres }}^{12}$, Jardim ${ }^{13}$ e Nortelândia' ${ }^{14}$. As escolhas dessas novas sedes justificavam-se pela grande demanda de candidatos nessas localidades. Segundo Rosa (1993), o interesse na cidade de Nortelândia era alto. Contudo, quando o curso foi

\footnotetext{
11 Glória de Dourados é uma cidade localizada a $267 \mathrm{~km}$ da capital do estado de Mato Grosso do Sul.

12 Cáceres é um município do estado de Mato Grosso que faz fronteira com a Bolívia.

13 Jardim é uma cidade sul-mato-grossense localizada a $234 \mathrm{~km}$ da capital estadual.

14 Nortelândia é um município do estado de Mato Grosso. Distam 250 km de Cuiabá.
} 
oferecido nesse município, em 1976, houve mais fases e, assim, o tempo de curso passou a ser de dois anos. As fases em Nortelândia foram dispostas do seguinte modo: a primeira e segunda fases ocorreram em janeiro e fevereiro de 1976, a terceira, em julho do mesmo ano, a quarta e quinta fases em janeiro e fevereiro de 1977, a sexta em julho de 1977, e a sétima e oitava fases ocorreram em janeiro e fevereiro de 1978. Formou-se, nesse polo, assim como nos demais, apenas uma turma.

Quadro 2: Fases do Curso de Licenciatura Parcelada de Curta Duração de Ciências, ministrado pelo polo de Corumbá nas cidades de Ponta Porã, Rondonópolis e Nortelândia (1973-1978)

\begin{tabular}{|l|l|l|l|l|l|l|l|l|}
\hline POLOS & 1 & 2 & 3 & 4 & 5 & 6 & 7 & 8 \\
\hline \multirow{2}{*}{ Ponta Porã } & Jul. & Jan. & Jul. & Jan. & Fev. & & & \\
& 1973 & 1974 & 1974 & 1975 & 1975 & - & - & - \\
\hline \multirow{2}{*}{ Rondonópolis } & Jul. & Jan. & Jul. & Jan. & Fev. & & & \\
& 1973 & 1974 & 1974 & 1975 & 1975 & - & - & - \\
\hline \multirow{2}{*}{ Nortelândia } & Jan. & Fev. & Jul. & Jan. & Fev. & Jul. & Jan. & $\begin{array}{l}\text { Fev. } \\
\end{array}$ \\
& 1976 & 1976 & 1976 & 1977 & 1977 & 1977 & 1978 & 1978 \\
\hline
\end{tabular}

Fonte: Acervo da UFMS - Universidade Federal de Mato Grosso do Sul

O acesso a esses dados levou-nos a questionar sobre o que se alterou na estrutura curricular dessa Licenciatura de 1973 para 1976. Voltamos a estudar todas as grades curriculares e constatamos que Ponta Porã e Rondonópolis tiveram o mesmo programa. Contudo, devido à disposição das fases, algumas disciplinas foram reorganizadas.

Quadro 1: Estrutura Curricular do Curso de Licenciatura Parcelada de Curta Duração de Ciências, ministrado em Ponta Porã e Rondonópolis (1973-1975)

\begin{tabular}{|c|l|c|}
\hline \multirow{2}{*}{ Fases } & \multicolumn{1}{|c|}{ Disciplinas } & Carga Horária \\
\hline \multirow{3}{*}{$1^{a}$ Fase } & Elementos de Geologia & 60 \\
\cline { 2 - 3 } & Química Geral I & 60 \\
\cline { 2 - 3 } & Fundamentos de Matemática & 120 \\
\cline { 2 - 3 } & Desenho Geométrico I & 45 \\
\hline $2^{a}$ Fase & Psicologia da Educação & 45 \\
\hline
\end{tabular}




\begin{tabular}{|c|c|c|}
\hline & Desenho Geométrico II & 45 \\
\hline & Química Geral II & 60 \\
\hline & Botânica & 90 \\
\hline & Teoria dos Números & 120 \\
\hline & Biologia Geral & 105 \\
\hline & Física Geral e Experimental I & 75 \\
\hline & Química Inorgânica e Analítica & 60 \\
\hline 2a Egco & Zoologia I & 45 \\
\hline s ruse & Física Geral e Experimental II & 75 \\
\hline & Práticas Desportivas & 30 \\
\hline & Zoologia I & 45 \\
\hline & Química Orgânica I & 45 \\
\hline & Química Orgânica II & 45 \\
\hline $4^{a}$ Fase & $\begin{array}{l}\text { Estrutura e Funcionamento do Ensino } \\
\text { de } 1^{\circ} \text { grau }\end{array}$ & 60 \\
\hline & Didática & 75 \\
\hline & Prática de Ensino de Ciências & 120 \\
\hline & Estudo de Problemas Brasileiros & 30 \\
\hline & Física Geral e Experimental III & 60 \\
\hline Carga Horár & & 1.560 \\
\hline
\end{tabular}

Fonte: Acervo da UFMS - Universidade Federal de Mato Grosso do Sul

As disciplinas de Matemática concentravam-se, nessa estrutura curricular, na primeira e segunda fases, totalizando 330 horas. Porém, em Rondonópolis, Teoria dos Números foi dividida em Teoria dos Números I (na segunda fase) e Teoria dos Números II (trabalhada nas terceira e quarta fases), cada uma com 60 horas aula. Já em Nortelândia, a estrutura curricular foi disposta do modo apresentado no quadro a seguir:

Quadro 4: Estrutura Curricular do Curso de Licenciatura Parcelada de Curta Duração de Ciências, ministrado em Nortelândia (1976-1978)

\begin{tabular}{|c|l|c|}
\hline Fases & \multicolumn{1}{|c|}{ Disciplinas } & Carga Horária \\
\hline \multirow{3}{*}{$1^{a}$ Fase e } & Química Geral I & 60 \\
\cline { 2 - 3 } $2^{a}$ Fase & Matemática I & 60 \\
\cline { 2 - 3 } & Trigonometria & 60 \\
\cline { 2 - 3 } & Biologia Geral I & 60 \\
\hline
\end{tabular}




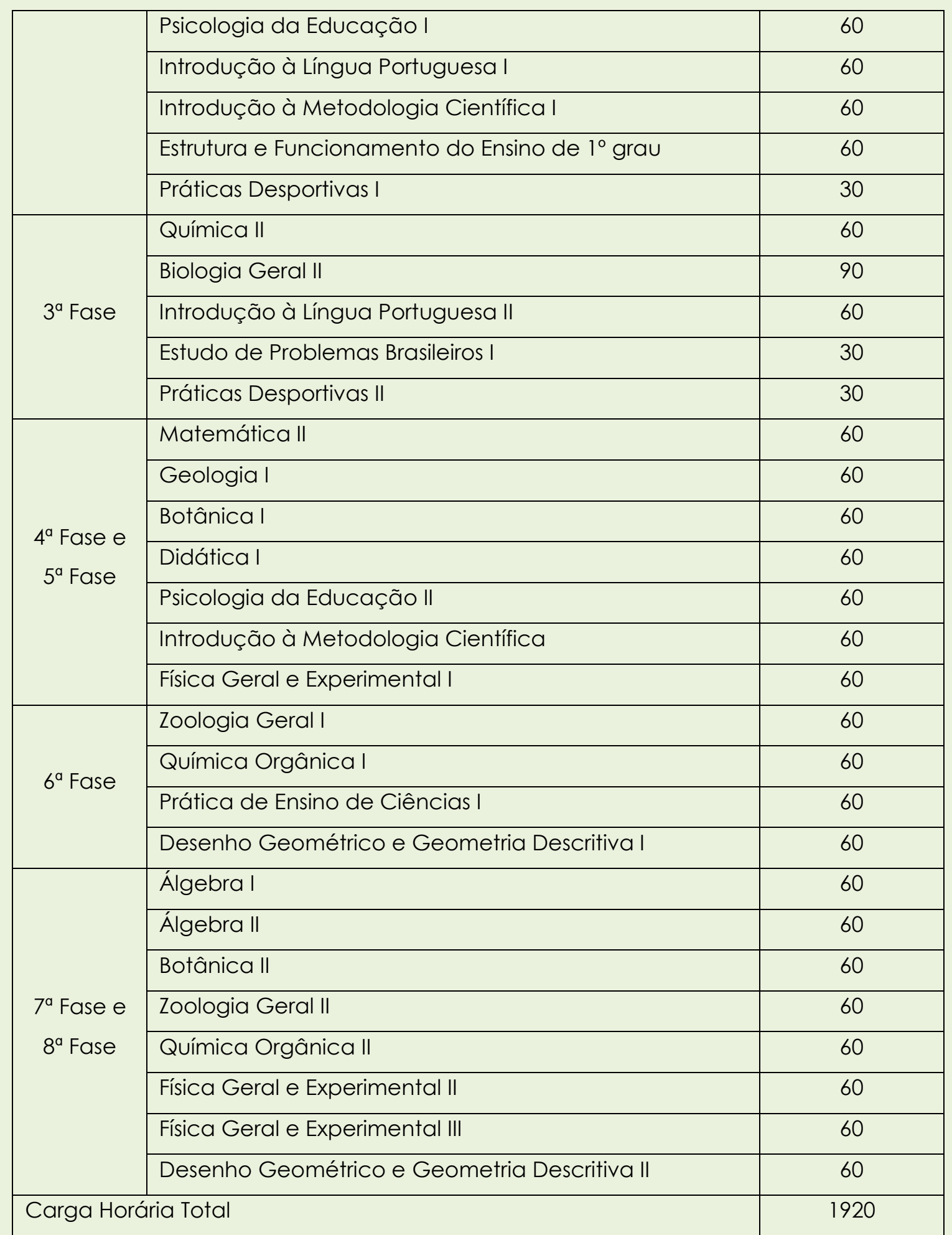

Fonte: Acervo da UFMS - Universidade Federal de Mato Grosso do Sul

Como o curso passou a ter 1920 horas, foi necessário ampliar a quantidade e a duração das fases. Observamos ainda que várias disciplinas foram acrescidas a essa nova estrutura curricular. Algumas disciplinas de Matemática tiveram a sua nomenclatura alterada - como, por exemplo, 
Fundamentos de Matemática (que passou a ser denominada Matemática I e II). A disciplina Teoria dos Números foi excluída dessa nova proposta, e Álgebra I, Álgebra || e Trigonometria | foram acrescentadas à grade curricular. Com tais exclusões e incorporações, as disciplinas de Matemática passaram a totalizar 420 horas no conjunto das disciplinas do curso.

É preciso ter em mente que o curso das Licenciaturas Parceladas de Curta Duração de Ciências habilitava professores nas áreas de Química, Física, Biologia e Matemática. As disciplinas foram implantadas de modo que os alunos-professores tivessem formação mínima necessária para atuar no então primeiro grau, o que parece justificar, por exemplo, a exclusão da disciplina Teoria dos Números da grade curricular.

\section{Dois modos de formação em um mesmo tempo: comentários finais}

Nosso objetivo central é discutir os modos como a Matemática se configura disciplinarmente nos cursos de Ciências, regular e parcelado, oferecidos no Sul do Mato Grosso Uno. Ao compararmos as grades curriculares temos subsídios para a discussão sobre o processo de formação de professores que, nesse estado, ensinam matemática na década de 1970.

Um primeiro aspecto, já apontado por nós, se refere à legislação que dispunha sobre a criação e manutenção de cursos de curta duração. No que diz respeito à parte comum, qual seja, as disciplinas de Matemática, Física, Química, Biologia e Elementos de Geologia, as duas estruturas estudadas atendiam a exigência da Resolução CFE 30/1974. Além, é claro, das disciplinas pedagógicas exigidas por lei.

Quadro 5 - Comparação entre as disciplinas de Matemática das estruturas de cursos de Ciências regular e parcelada

\begin{tabular}{|l|l|l|c|}
\hline \multicolumn{2}{|c|}{ Curso Ciências Regular } & \multicolumn{2}{c|}{ Curso Ciências Parcelado } \\
\hline Disciplina & C.H. & Disciplina & C.H. \\
\hline Álgebra I & 60 & Álgebra I & 60 \\
\hline Álgebra II Álgebra II & 60 & Á & 60 \\
\hline $\begin{array}{l}\text { Desenho Geométrico e Geometria } \\
\text { Descritiva I }\end{array}$ & 60 & $\begin{array}{l}\text { Desenho Geométrico e } \\
\text { Geometria Descritiva I }\end{array}$ & 60 \\
\hline
\end{tabular}




\begin{tabular}{|l|l|l|c|}
\hline $\begin{array}{l}\text { Desenho Geométrico e Geometria } \\
\text { Descritiva II }\end{array}$ & 60 & $\begin{array}{l}\text { Desenho Geométrico e } \\
\text { Geometria Descritiva II }\end{array}$ & 60 \\
\hline Elementos de Estatística & 60 & & 60 \\
\hline Fundamentos de Matemática I & 90 & Matemática I & 60 \\
\hline Fundamentos de Matemática II & 90 & Matemática II & 60 \\
\hline Trigonometria & 60 & Trigonometria & 1.920 \\
\hline Carga horária total do curso & 2.205 & Carga horária total do curso & 420 \\
\hline $\begin{array}{l}\text { Carga horária total das disciplinas de } \\
\text { Matemática }\end{array}$ & 540 & $\begin{array}{l}\text { Carga horária total das } \\
\text { disciplinas de Matemática }\end{array}$ & 4 \\
\hline
\end{tabular}

Fonte: Tabela elaborada pelas autoras

A partir dessa primeira comparação podemos notar que as disciplinas ofertadas nas duas modalidades de ensino eram praticamente as mesmas, com a mesma nomenclatura e mesma carga horária. Algo muito similar ocorre ainda hoje nas estruturas curriculares do Curso de Matemática, licenciatura, modalidade à distância, e do Curso de Matemática, licenciatura (presencial), oferecidos pelo Instituto de Matemática da UFMS. Estruturas muito próximas, porém executadas de modos e em tempos e movimentações muito distintos, dada a natureza de cada modalidade.

O grande diferencial, portanto, nos parece ser o modo como essas disciplinas eram oferecidas. Enquanto no curso regular o aluno tinha um semestre para discutir os conteúdos das disciplinas, no curso parcelado, os mesmos assuntos deveriam ser discutidos em um mês. Essa comparação entre as estruturas curriculares é reforçada se considerarmos as discussões de Gonzales (2017), em pesquisa que já anunciava, a partir da análise de entrevistas, a semelhança das grades e as diferentes condições de trabalhar essa grade nas distintas modalidades de formação. Maria Luiza da Silva Correa relembra que a estrutura das Licenciaturas Parceladas de Curta Duração de Ciências oferecidas em Corumbá/Rondonópolis15, "em termos

\footnotetext{
${ }^{15}$ As Licenciaturas Parceladas de Curta Duração de Ciências oferecidas em Corumbá tinham como objetivo atender ao polo de Nortelândia, já que o aluno Antônio, nosso entrevistado, fez esse último curso em 1976 e que, em seu histórico escolar, consta ter sido o curso realizado em Nortelândia. Assim, segundo ele, "O curso foi iniciado em Corumbá, e se não me falha a memória, fomos fechar com os professores João Quintilio Ribeiro e com o Masao em um lugar chamado Nortelândia".
} 
de ementa, plano de ensino e carga horária, era semelhante a do curso regular. Até os professores eram os mesmos. Contudo havia um diferencial: as aulas eram concentradas [...]". Ela ainda reforça que, para fazer esse curso, "[...] necessitava de dedicação dos alunos quase o dia todo durante o tempo do curso, que geralmente era nas férias".

Segundo o depoimento do professor Masao Uetanabaro: "[...] a carga horária era a mesma do curso que acontecia regularmente, pois caso contrário eles não poderiam obter o diploma". A importância de manter o paralelismo entre as modalidades de formação - em termos de disciplinas e carga horária - bem provavelmente era um discurso muito difundido, inclusive para legitimar a formação parcelada em relação à formação "regular", já que o parcelamento do curso era visto com certa desconfiança.

Os cursos eram, por suas próprias naturezas, muito distintos, mas a necessidade de validar um pela comparação com o outro se faz muito presente nas entrevistas disponíveis em Gonzales (2017), o que pode ser facilmente depreendido também quando consideramos as grades, como fizemos aqui. A semelhança entre as estruturas se sustenta ainda por ambas as licenciaturas estarem regidas pela mesma legislação. Ou seja, para que o curso fosse autorizado, ao menos formalmente a estrutura deveria atender ao que determinava a lei.

A maior contribuição dos cursos de Ciências oferecidos na década de 1970 no Sul de Mato Grosso, nos parece ter sido a de formar professores para atuar na Educação Básica, ou seja, formar o professor para atuar em várias áreas de conhecimento em oposição a uma formação mais direcionada e específica.

Segundo o professor Carlos Henrique Patusco, os professores que atuavam no ensino de segundo grau na época eram todos professores contratados e, nas palavras dele, eram de "notório saber. Era tudo quebra galho". Desses professores que atuavam na rede e que se tornaram alunos dos cursos de formação de professores oferecidos pela Universidade, muitos 
eram formados em outras áreas, como arquitetos e dentistas, que atuavam no ensino básico. De acordo com o professor Carlos Henrique Patusco, até o seu próprio dentista foi seu aluno e atuava na rede. Esse fato também é mencionado pelo professor Sérgio Delvizio Freire, ressaltando que os professores que ministravam aulas no estado, antes de ocorrer a divisão do Mato Grosso Uno, eram oriundos do estado de São Paulo e, mesmo assim, muitos deles chegavam para lecionar sem formação específica. De acordo com $\circ$ Art. 78 da LDB 5692/1971, era facultada, na falta de professores licenciados para atender às necessidades do ensino, a profissionais diplomados em outros cursos de nível superior, a atuação no ensino público, desde que os profissionais fossem registrados no Ministério da Educação e Cultura. Ainda que, segundo essa disposição, também fosse necessária, além da formação superior em qualquer curso, uma complementação de estudos voltados à formação pedagógica, essa parte da disposição, aparentemente, era frequentemente negligenciada.

Ao compararmos as duas estruturas, o que podemos dizer sobre as disciplinas matemáticas nelas presentes? Elas cumpriam o papel de formar um professor polivalente, com trânsito entre as disciplinas da área comum? Um olhar geral sobre as estruturas ali propostas nos dá indícios de que, apesar de haver disciplinas de todas as áreas, como previsto pela Resolução 30, elas eram oferecidas de modo disjunto, sem qualquer menção àquela Ciência Integrada tomada como eixo da proposta.

Além disso, destaque-se a predominância de disciplinas que poderíamos chamar de "de conteúdo matemático". Praticamente um quarto do curso era voltado a essas disciplinas, 540 h. Esse aspecto quantitativo por nós observado é reforçado pelo fato de, em Aquidauana, a habilitação plena oferecida na década de 1980 ser apenas aquela para habilitação em Biologia. Algo parecido aconteceu no curso de Ciências da UCDB, que apesar de não ter sido explorado nesse texto, tinha habilitações plenas apenas em Biologia e Matemática.

Os indícios aqui presentes nos levam a inferir que, ainda que o curso tivesse por objetivo formar um professor que pudesse atuar nas cinco áreas 
correspondentes, havia uma tendência para as disciplinas de Matemática e Biologia, resultante do modo como as estruturas curriculares eram propostas ou mesmo devido à oferta de habilitações, sendo mais comuns aquelas em Matemática e Biologia.

\section{REFERÊNCIAS}

ALVES, G. L. As Licenciaturas Parceladas de curta duração dentro de uma política de formação de recursos humanos. Coleção Cadernos. Corumbá, MT. n.1. p. 01-63, 1973.

BITTAR, M. Mato Grosso do Sul a construção de um estado: Regionalismo e divisionismo no Sul de Mato Grosso. Campo Grande: Editora UFMS, 2009.

BITTAR, M.; SILVA, M.G.M.; VELOSO, T.C.M.A. Processo de interiorização da educação superior na região centro-oeste: particularidade dos estados de Mato Grosso e Mato Grosso do Sul. Série-Estudos. Dossiê Educação Superior. Campo Grande: UCDB, n.16, jul/dez.2003.p.147-164.

BOTH, B. C. Sobre a Formação de Professores de Matemática em Cuiabá - MT (1960 - 1980). 2014. 402 f. Dissertação (Mestrado) - Curso de Educação Matemática, Universidade Estadual Paulista - Unesp Rio Claro, Rio Claro, SP, 2014.

BRASIL. Lei n 4024, de 20 de dezembro de 1961. Fixa as diretrizes e bases da Educação Nacional. LDB. Brasilia, Disponível em:

<http://www.planalto.gov.br/ccivil_03/Leis/L4024.htm>. Acesso em: 28 ago. 2013.

BRASIL. Lei $n^{\circ}$ 5692, de 11 de agosto de 1971. Fixa as diretrizes e bases para o ensino de $1^{\circ}$ e $2^{\circ}$ graus, e dá outras providências. LDB. Brasília, Disponível em: <http://www.planalto.gov.br/ccivil_03/leis/l5692.htm>. Acesso em: 28 out. 2013.

CASTRO, A. D. de. A Licenciatura no Brasil. Revista de História, São Paulo, v. , n. 100, p.627-652, out./dez. 1974.

CHAGAS, V. Formação do Magistério: novo sistema. São Paulo. Atlas, 1976, p. 161.

CONSELHO FEDERAL DE EDUCAÇÃO. Resolução n 30, de 11 de julho de 1974. Fixa os mínimos de conteúdo e duração a observar na organização do curso de licenciatura em Ciências. CFE. Documenta, Brasília, (164): 509-1 1, jul. 1974.

CONSELHO FEDERAL DE EDUCAÇÃO. Resolução $n^{\circ} 37$, de 26 de março de 1975. Dispõe sobre a implantação progressiva do curso de licenciatura em 
Ciências, a que se refere a Resolução n 30/74. Alterado pela R. 05/1978. CFE. Diário Oficial, Brasília, 26 de março de 1975. Seção 1, pt. 1, p. 3.635.

FAORO, T. C. T. A formação de professores de Matemática da Universidade Federal de Mato Grosso do Sul: um olhar sobre os anos iniciais da Licenciatura em Dourados. 2014. 236 f. Dissertação (Mestrado) - Curso de Mestrado em Educação Matemática, Universidade Federal de Mato Grosso do Sul, Campo Grande, 2014.

GONZALES, K. G. Formar professores que ensinam Matemática: uma história do movimento das Licenciaturas Parceladas no Mato Grosso do Sul. 534f. Tese (Doutorado) - Universidade Estadual Paulista. Faculdade de Ciências, Bauru, 2017.

MARTINS-SALANDIM, M. E.; FERNANDES, D.; GARNICA, A. V. M. A Formação de Professores de Matemática no Brasil: de temas possíveis e do tratamento da periodização na produção de um grupo de pesquisa. Anais: Atas do I Congresso Ibero-Americano de História da Educação Matemática. Covilhã: UBI, 2011

QUEIROZ, P. R. C. Mato Grosso/Mato Grosso do Sul: divisionismo e identidades (um breve ensaio). Diálogos, v. 10, n. 02, p. 149-184, 2006.

ROSA, J. P. da. As duas histórias da Universidade: 1966 - 1978. Campo Grande-MS. ACS/RTR: UFMS, 1993, 120 p.

SILVA, C. R. M. da. Uma, Nove ou Dez Narrativas sobre as Licenciaturas em Ciências e Matemática em Mato Grosso do Sul. Tese (Doutorado em Educação Matemática) - Universidade Estadual Paulista - Unesp, Rio Claro, 2015.

Recebido em: 28 de setembro de 2018 Aprovado em: 17 de abril de 2019 